\title{
Journal of Toxicologic Pathology
}

Received : March 22, 2021

Accepted : January 7, 2022

J-STAGE Advance Published Date : February 26, 2022 


\section{LPS-TLR4/MD-2-TNF- $\alpha$ signaling mediates alcohol-induced liver fibrosis in rats}

Wen-Ling Mou ${ }^{1, \#, *}$, Shi-ru Chen ${ }^{1, \#}$, Zhen-ting Wu ${ }^{1}$, Li-hua Hu ${ }^{1}$, Ji-ye Zhang ${ }^{1}$, Hong-jie Chang ${ }^{1}$, Hang

Zhou $^{1}$, Ying Liu ${ }^{1, *}$

${ }^{1}$ Department of Gastroenterology, Heilongjiang Province Hospital, Harbin 150000, China

\#Shi-ru Chen and Wen-Ling Mou contributed equally to this study.

Running title: LPS-TLR4/MD-2-TNF- $\alpha$ and liver fibrosis

\section{*Co-Corresponding authors:}

Dr. Wen-Ling Mou and Ying Liu

Department of Gastroenterology, Heilongjiang Province Hospital

No. 82, Zhongshan Road, Xiangfang District, Harbin 150000, China

Tel: +86-13946150118 (Wen-Ling Mou) and +86-13845007000 (Ying Liu)

Fax: +86-451-88025114

Email: mouwenling18_hph@163.com (Wen-Ling Mou) and anzi1975@sina.com (Ying Liu) 


\section{Abstract}

Liver fibrosis results from liver inflammation and progresses to liver cirrhosis or liver cancer. It is known that nonalcoholic liver disease is mediated by the Toll-like receptor 4 (TLR4)/myeloid differentiation factor-2 (MD-2)-tumor necrosis factor-alpha (TNF- $\alpha$ ) signaling pathway. This study aimed to investigate whether alcoholic liver disease is also mediated by this pathway. To this end, we first established rat models of liver fibrosis by administering alcohol. Next, the rats were injected with anti-TLR4 and anti-MD-2 antibodies. RT-qPCR and Western blotting were used to detect the activation of the TLR4/MD-2-TNF- $\alpha$ signaling pathway and hepatic stellate cells (HSCs). Moreover, the expression of molecules related to liver fibrosis was estimated. The morphology of rat liver tissue was observed through hematoxylin-eosin staining and Masson staining. For in vitro studies, Kupffer cells (KCs) isolated from the liver were transfected with si-TLR4 and si-MD-2 and co-cultured with HSCs to determine the activity of HSCs. It was found that alcohol treatment activated the TLR4/MD-2TNF- $\alpha$ signaling pathway and upregulated the molecules associated with liver fibrosis. However, inhibition of TLR4 and MD-2 partially reversed this trend. Notably, in vitro studies indicated that knockdown of TLR4 and MD-2 in KCs partially inhibited LPS-induced activation of KCs and HSCs. Overall, this study showed that alcohol induces liver fibrosis via the LPS-TLR4/MD-2-TNF- $\alpha$ signaling pathway.

Keywords: Hepatic fibrosis; TLR4/MD-2; Kupffer cells; Hepatic stellate cells 


\section{Introduction}

Liver fibrosis results from the healing reaction of inflammatory injury of the liver caused by alcohol, drugs, and autoimmunity ${ }^{1,2}$. In the absence of timely treatment, liver fibrosis progresses to liver cirrhosis, hepatic failure, or even liver cancer ${ }^{3,4}$. Fibrosis is characterized by abnormal deposition of the extracellular matrix (ECM) in the liver, which is usually reversible at a specific stage. However, once cirrhosis is formed, the change is almost irreversible ${ }^{5,6}$. Worldwide, the number of deaths from liver cirrhosis and cancer is rising, with a very high mortality rate due to late diagnosis ${ }^{7}$. Therefore, to avoid the transformation of liver fibrosis into advanced cirrhosis or cancer, it is vital to develop effective anti-fibrosis methods for the clinical management of liver fibrosis.

Inflammation is a pivotal process in the occurrence and development of liver fibrosis, where hepatic macrophages play a major role ${ }^{8}$. Kupffer cells (KCs), a type of hepatic macrophages, produce pro-inflammatory factors, such as tumor necrosis factor-alpha (TNF- $\alpha$ ), interleukin (IL)-1 $\beta$, and macrophage inflammatory protein $1 \alpha$ (MIP-1 $\alpha$ ), that promote the activation of hepatic stellate cells (HSCs) ${ }^{9,10}$. Previous studies have shown that activated HSCs are the key effector cells that cause an abnormal increase in ECM deposition in liver fibrosis ${ }^{11,12}$. The pathogenesis of liver fibrosis involves cell damage and the release of inflammatory factors that prompt the activation and transformation of resting HSCs into astromyofibroblasts ${ }^{13-15}$. Moreover, HSCs have higher proliferation rates and release inflammatory and pro-proliferative factors. Notably, during the recovery of liver fibrosis, the apoptosis of HSCs increases significantly ${ }^{16,17}$. Tissue inhibitor of metalloproteinase-1 (TIMP-1) plays an important role in the pathogenesis of liver fibrosis, and its expression in HSCs is enhanced by TNF- $\alpha^{18,}$

${ }^{19}$. Some studies have shown that after $\mathrm{CCl}_{4}$ treatment, liver fibrosis in transgenic mice overexpressing TIMP-1 in the liver increased ${ }^{20}$. 
Until now, liver biopsy is the most common and effective method to identify liver fibrosis and cirrhosis $^{21}$. However, liver biopsy is characterized by high consumption, low patient acceptance, increased risk of complications, and low replicability ${ }^{21}$. Therefore, the molecular mechanism of liver fibrosis has been studied extensively to find a safer and more feasible detection method. Fortunately, significant progress has been made in this regard. For example, IL-33 was identified as an activator of HSCs that induce hepatic fibrosis, inhibition of the nuclear factor kappa-B $(\mathrm{NF}-\kappa \mathrm{B})$ and mitogen-activated protein kinase (MAPK) signaling pathways improves liver fibrosis, and antiplatelet drugs prevent liver fibrosis ${ }^{2,22-24}$. LPS is a known endotoxin found in the outer membrane of many intestinal gram-negative bacteria ${ }^{25}$. Previous studies have shown that LPS induces the expression of Toll-like receptor 4 (TLR4) and myeloid differentiation factor-2 (MD-2, co-receptor of TLR4) in KCs and produces TNF- $\alpha$ in nonalcoholic liver disease ${ }^{26,27}$. Moreover, the TLR4/MD-2-TNF- $\alpha$ signaling pathway that mediates the activation of KCs is induced by LPS ${ }^{28,29}$. However, it is not known whether alcohol-induced alcoholic liver disease is linked to the LPS-TLR4/MD-2-TNF- $\alpha$ signaling pathway. Therefore, this study aimed to investigate the effect of ethanol on liver disease via the modulation of the LPS-TLR4/MD-2-TNF- $\alpha$ signaling pathway.

\section{Materials and Methods}

\section{Animals and treatment}

Twenty-four male Wistar rats, weighing $200 \pm 20 \mathrm{~g}$, were purchased from Beijing Vital River Laboratory Animal Technology Co., Ltd, Beijing, China. This study was performed according to the experimental protocol approved by the Ethics Committee of Heilongjiang Province Hospital. After 1 week of adaptation to general meals, the rats were randomly divided into four groups $(\mathrm{n}=6$ rats in each 
group): the control group $(\mathrm{Ctrl})$ and the ethanol groups $(\mathrm{EtOH})$. The rats in the EtOH groups were subjected to intragastric administration of ethanol solution $(40 \% \mathrm{v} / \mathrm{v})$, dissolved in $40 \mathrm{~g}$ anhydrous ethanol in distilled water to prepare $100 \mathrm{~mL} ; 10 \mathrm{~mL} / \mathrm{kg} / \mathrm{d}$, Aladdin, Shanghai, China), once a day for 12 weeks. In this study, the method of establishing a rat alcoholic liver injury model was improved on the basis of existing methods ${ }^{30}$. The two groups of ethanol-fed rats were injected with anti-TLR4 (ab217274, dilution 1/300, $0.2 \mathrm{mg} / \mathrm{kg}$, once per week, Abcam, Cambridge, UK) and anti-MD-2 antibodies (ab24182, dilution $0.5 \mu \mathrm{g} / \mathrm{mL}, 0.2 \mathrm{mg} / \mathrm{kg}$, once per week, Cambridge, UK) via the caudal vein to verify whether TLR4/MD-2 plays a role in alcoholic liver fibrosis from the fifth week until the end of the experiment, which lasted for 8 weeks. The antibody dilution was recommended by the manufacturer, and the dosage was the optimal dosage selected after the pre-experiment. Meanwhile, the rats in the control group were administered with saline $(\mathrm{NaCl}$, Merck, Darmstadt,

Germany) by gavage once a day for 12 weeks. The rats were intraperitoneally injected with $4 \%$ pentobarbital (Merck, $30 \mathrm{mg} / \mathrm{kg}$ ) and killed by cervical dislocation. The plasma samples were collected and stored at $-80^{\circ} \mathrm{C}$ for further analysis. The liver tissue was quickly removed from the abdominal cavity and divided into three equal parts. One part was fixed in 10\% formalin at room temperature (RT) for $24 \mathrm{~h}$ for histopathological examination, the other part was used for the separation of KCs and HSCs and the detection of cytokines, and the last part was rapidly frozen in liquid nitrogen and stored at $-80^{\circ} \mathrm{C}$.

\section{Cell isolation}

KCs were isolated from the rat liver through collagenase digestion in vitro and differential centrifugation ${ }^{31,32}$. First, 12 male SPF-Wistar rats were anesthetized through the intraperitoneal injection of pentobarbital sodium $(50 \mathrm{mg} / \mathrm{kg})$. After abdominal incision, $500 \mathrm{~mL}$ PBS buffer solution 
$\left(37^{\circ} \mathrm{C}, 30 \mathrm{~mL} / \mathrm{min}\right)$ was infused through the hepatic portal vein to remove the red blood cells, and then the liver was removed. Next, the minced liver was digested in MDEM with $0.1 \%$ type IV collagenase in a $37^{\circ} \mathrm{C}$ water bath for $30 \mathrm{~min}$, and the liver homogenate was filtered through a 200 -gauge mesh. The filtrate was centrifuged at $50 \times \mathrm{g}$ for 2 min to collect the suspension of $\mathrm{KCs}$ and HSCs. The suspension was recentrifuged at $500 \times \mathrm{g}$ for $7 \mathrm{~min}$ at $4^{\circ} \mathrm{C}$ to collect the cell pellet. The cell precipitate was added to a mixture of Nycodenz (Merck, Darmstadt, Germany) and PBS and centrifuged at 1,500 $\times \mathrm{g}$ for $17 \mathrm{~min}$ at $4^{\circ} \mathrm{C}$. HSCs were collected from the interface and washed three times with PBS. These were cultured in MDEM with $10 \% \mathrm{FBS}$ and $100 \mathrm{U} / \mathrm{mL}$ penicillin/streptomycin at $37^{\circ} \mathrm{C}$ and $5 \% \mathrm{CO}_{2}$. The culture medium was changed every $24 \mathrm{~h}$.

After the removal of HSCs, the remaining part of the sample was washed three times with PBS and centrifuged to purify the KCs. The cells were seeded in a 16-well plate and cultured in serum-free DMEM. After $2 \mathrm{~h}$, the nonadherent cells were removed by washing with PBS. The purified KCs were cultured in MDEM with $10 \% \mathrm{FBS}$ and $100 \mathrm{U} / \mathrm{mL}$ penicillin/streptomycin at $37^{\circ} \mathrm{C}$ and $5 \% \mathrm{CO}_{2}$. The culture medium was changed every $24 \mathrm{~h}$.

Finally, KCs and HSCs were identified using cell markers and flow cytometry, and the trypan blue exclusion assay and the ink particle phagocytosis test were used to estimate the viability and phagocytic activities of the KCs and HSCs, respectively. Antibodies for flow cytometry included the anti-CD68 antibody (EPR23917-164] (ab283654, dilution 1/500, Cambridge, UK) and anti- $\alpha$-smooth muscle actin ( $\alpha$-SMA) antibody (14A) (ab7817, dilution $1.137 \mu \mathrm{g} / \mathrm{mL}$, Cambridge, UK).

\section{Co-culturing of the cells}

After $1 \mathrm{~d}$ of culture, KCs were divided into four groups. In the control group, KCs were cultured in DMEM supplemented with 10\% FBS and normal saline. In the LPS group, the KCs were stimulated 
with LPS (100 ng/mL) for $6 \mathrm{~h}$. In the LPS + si-TLR4 and LPS + si-MD-2 groups, the KCs were stimulated with LPS and transfected with the siRNA plasmids si-TLR4/si-MD-2 using the Lipofectamine 2000 reagent (Invitrogen, Barcelona, Spain). The plasmids were synthesized commercially by Sangon, Shanghai, China. After 2 days, each group was co-cultured with HSCs in the Boyden chamber and the cell culture inserts, polyethylene terephthalate membrane (pore size $8 \mu \mathrm{m}$ ). The HSCs $\left(1.5 \times 10^{5}\right.$ cells $)$ were plated in the bottom plates and cultured in DMEM with $10 \%$ FBS. After 1 day, the medium was removed. KCs $\left(4.5 \times 10^{5}\right.$ cells $)$ were plated on cell culture inserts and transferred onto the HSCs. Empty inserts were used as co-culture controls. Next, $4 \mathrm{~mL}$ DMEM without serum was added to the chamber. After 2 days, the HSCs in the bottom plates were used for the MTT assay.

\section{Liver histopathology}

The rat liver tissue was fixed with $10 \%$ formalin and cut into $4-\mu \mathrm{m}$-thick slices using the paraffin slice technique. To observe the histological changes in liver injury, one part of the section was stained with hematoxylin and eosin $(\mathrm{H} \& \mathrm{E})$, whereas the other part was used to investigate hepatic collagen deposition through Masson's trichrome staining. The degree of liver injury was estimated based on the infiltration of inflammatory cells under a light microscope (Olympus, Tokyo, Japan).

\section{Western blotting}

Western blotting was used to detect the protein levels linked to hepatic fibrosis, including collagen I, $\alpha$-SMA, TIMP-1, TLR4, MD-2, TNF- $\alpha$, IL-1 $\beta$, and MIP-1 $\alpha$. The total protein fraction was extracted from the liver homogenate or KC cell lysate using the Total Protein Extraction Kit (BestBio, Shanghai, China). The protein concentrations of the samples were estimated using the BCA Protein Assay Kit (HaiGene, Harbin, China). Protein samples (10 $\mu \mathrm{g}$ each) were separated through electrophoresis using 
10\% SDS-PAGE and transferred onto polyvinylidene difluoride membranes. After blocking with 5\% nonfat milk at $25^{\circ} \mathrm{C}$ for $1 \mathrm{~h}$, the membranes were incubated overnight with primary antibodies against collagen I (ab34710, dilution 1/10,000, Abcam), $\alpha$-SMA (\#149685, dilution 1/1,000, Cell Signaling Technology, MA, USA), TIMP-1 (ab211926, dilution 1/1,000), TLR4 (ab13556, dilution 1/500), MD-2 (ab241182, dilution $1 \mu \mathrm{g} / \mathrm{mL}$ ), TNF- $\alpha$ (ab215188, dilution 1/1,000), IL-1 $\beta$ (ab2105, dilution 1/2,000), and MIP-1 $\alpha$ (sc-365691, dilution 1:800, Santa Cruz Biotechnology, California,USA) at $4{ }^{\circ} \mathrm{C}$.

Subsequently, the membranes were incubated with secondary antibodies anti-goat anti-rabbit IgG H\&L (HRP) (ab205718, dilution 1/50,000) or goat anti-mouse IgG H\&L (HRP) (ab6789, dilution 1/10,000) for $1 \mathrm{~h}$ at $37^{\circ} \mathrm{C}$. The protein bands were visualized with the electrochemiluminescence Western blotting kit (Thermo Fisher Scientific, MA, USA) and immediately exposed to autoradiography film. $\beta$-Actin was used as an internal control.

\section{ELISA}

Enzyme-linked immuno sorbent assay (ELISA) was used to estimate the levels of hydroxyproline and alanine aminotransferase (ALT), which are markers of liver function. The assay was performed according to the instructions of the Hydroxyproline ELISA Kit (ASB-OKEH025, ENZO) and ALT ELISA Kit (ab234579, Abcam). Standards/samples (50 $\mu \mathrm{L} /$ well) were added to the appropriate wells of 96-well plates. Subsequently, a $50 \mu \mathrm{L}$ antibody cocktail was added to all wells and co-cultured for $1 \mathrm{~h}$ at $25^{\circ} \mathrm{C}$. Next, all wells were washed three times with $350 \mu \mathrm{L}$ of $1 \mathrm{X}$ wash buffer. Next, $100 \mu \mathrm{L}$ TMB development solution was added to each well and incubated for $10 \mathrm{~min}$. The reaction was stopped with $100 \mu \mathrm{L}$ stop solution. Finally, the optical density was recorded at $450 \mathrm{~nm}$ using a microplate reader.

\section{Reverse transcription quantitative polymerase chain reaction}

Reverse transcription quantitative polymerase chain reaction (RT-qPCR) was used to estimate the 
expression of TLR4, MD-2, and TNF- $\alpha$ in liver tissue and CD68, TNF- $\alpha$, IL-1 $\beta$, and MIP-1 $\alpha$ in KCs. Liver tissue (100 mg) was ground with liquid nitrogen, and total RNA was extracted from the homogenate using TRIzol (Invitrogen). Next, the total RNA was reverse-transcribed to cDNA using SuperScript ${ }^{\mathrm{TM}}$ II Reverse Transcriptase (Invitrogen) according to the manufacturer's instructions. Then, a $20 \mu \mathrm{L}$ PCR reaction system including cDNA, primers, and PCR reaction solution was set up for RT-qPCR with QuantStudio ${ }^{\text {TM }} 5$ Real-Time PCR System (Thermo Fisher Scientific, Shanghai, China) and PowerTrack ${ }^{\mathrm{TM}}$ SYBR Green Master Mix (Thermo Fisher Scientific, Shanghai, China). RT-qPCR reaction conditions were as follows: $95^{\circ} \mathrm{C}$ for $8 \mathrm{~min}, 95^{\circ} \mathrm{C}$ for $4 \mathrm{~s}(45$ cycles $), 65^{\circ} \mathrm{C}$ for $6 \mathrm{~s}$, and $72^{\circ} \mathrm{C}$ for $1 \mathrm{~min}$. GAPDH was used as an internal control, and the $2^{-\Delta \Delta \mathrm{Ct}}$ method was used to estimate the relative expression levels ${ }^{33}$. Each experiment was repeated thrice. The primer sequences used in RT-qPCR are listed in Table 1.

MTT 3-(4,5-dimethylthiazol-2-yl)-2,5-diphenyl tetrazolium bromide) assay

The viability of HSCs was determined using the MTT assay. Briefly, $2 \times 10^{5}$ cells $/ \mathrm{mL}$ was inoculated into a 96-well plate. Then, $100 \mu \mathrm{L}$ MTT or control (dimethyl sulfoxide, DMSO) and $900 \mu \mathrm{L}$ DMEM with $10 \%$ FBS and $100 \mathrm{U} / \mathrm{mL}$ penicillin/streptomycin were added to each well. HSCs were allowed to grow for $3 \mathrm{~h}$ at $37^{\circ} \mathrm{C}$. MTT was reduced to blue crystals by metabolically active cells, which were dissolved in $100 \mu \mathrm{L}$ DMSO. Finally, absorbance was measured at $570 \mathrm{~nm}$ using a UV-Vis spectrophotometer. The GraphPad Prism 7.0 program was used to calculate the viability of KCs.

\section{Immunofluorescence studies}

An immunofluorescence assay was used to observe the expression of CD68, a marker of KCs in the rat liver. First, the liver sections were infiltrated with PBS containing 0.5\% Triton X-100. Next, the sections were incubated with $10 \%$ normal goat serum at RT. After $1 \mathrm{~h}$, the sections were incubated 
overnight with mouse anti-CD68 antibody (Abcam, ab201340, dilution $1-2 \mu \mathrm{g} / \mathrm{mL}$ ) at $4^{\circ} \mathrm{C}$. Later, the cells were washed thrice with PBS and incubated with the goat anti-mouse IgG Alexa 488 conjugated fluorescence secondary antibody (Invitrogen, R37120, dilution 1/1,000) for $1 \mathrm{~h}$ at RT. Finally, the sections were stained with 4',6-diamidino-2-phenylindole (DAPI) and observed under a confocal microscope. The DAPI group was used as a control group, and the PBS replaced the primary antibody as a negative control.

\section{Statistical analysis}

All data are presented as the mean \pm standard deviation. Statistical analysis was performed using GraphPad Prism software (version 7.0, GraphPad Software,California,USA). One-way ANOVA followed by Sidak's multiple comparisons test or Student's t-test was used to perform statistical evaluation. Statistical significance was set at $\mathrm{p}<0.05$. Each experiment was performed in triplicates.

\section{Results}

Alcohol administration induced liver fibrosis and activated TLR4/MD-2-TNF- $\alpha$ pathway in the model group of rats

To establish a model of hepatic fibrosis, rats were subjected to the intragastric administration of alcohol. Liver tissue was sectioned and used for histological analysis (H\&E and Masson). Meanwhile, using the liver homogenate, Western blot, ELISA, and RT-qPCR assays were performed to determine the levels of molecules associated with liver fibrosis. In the control group, the structure of hepatic lobules was clear, and the hepatocytes were orderly arranged (Fig. 1A). In the model group, hepatocytes were swollen, cytoplasm was loose, and inflammatory cells infiltrated the portal area, accompanied by punctate hepatocyte necrosis and the formation of a pseudolobule structure (Fig.1 A). We observed that compared to that in normal rats, the liver in the model group was denatured and necrotic, and the 
presence of a large area of pseudolobular tissue structure illustrated that the rat liver in the model group was cirrhotic (Fig. 1A). In the control group, the structure of hepatic lobules was clear, basically no collagen fiber distribution in the interlobular and portal areas were found, and only slight collagen fibers could be seen near the central vein (Fig. 1B). In the model group, a large number of collagen fibers and pseudolobules in the portal area were observed (Fig. 1B). Meanwhile, Western blotting analysis showed that the levels of proteins related to liver fibrosis, such as collagen I, $\alpha$-SMA, and TIMP- ${ }^{34}$, were higher in the model group than that in the control group (Fig. 1C). Similarly, ELISA revealed that hydroxyproline (Fig. 1D) and ALT (Fig. 1E) were upregulated in the model group. Importantly, RT-qPCR and Western blotting analyses revealed that TLR4, MD-2, and TNF- $\alpha$ were significantly increased in the model group compared to that in the control group (Fig. 1F-G). Overall, these results indicated liver fibrosis and activation of the TLR4/MD-2-TNF- $\alpha$ pathway in the model group of rats.

\section{Inhibition of TLR4/MD-2 alleviated partially alcohol-induced liver fibrosis}

To substantiate the regulatory effect of TLR4/MD-2 in alcoholic liver fibrosis, the rats were injected with antibodies anti-TLR4/MD-2 to inhibit their expression. The results of RT-qPCR and Western blot assays showed that inhibition of TLR4 or MD-2 could partially reduce the levels of TLR4, MD-2, and TNF- $\alpha$ induced by alcohol (Fig. 2A-B). In addition, the antibodies reduced the expression of TLR4 and MD-2 by 53\% and 33\%, respectively (Fig. 2B). Moreover, compared to that in the control group, HE staining of liver tissue indicated that the liver was severely damaged with a large number of pseudolobules in the EtOH group (Fig. 2C). Interestingly, inhibition of TLR4 or MD-2 partially alleviated alcohol-induced liver damage in rats (Fig. 2C). In addition, Masson staining showed that a large number of collagen fibers were deposited around the central vein, hepatocytes, and portal area, 
the portal area was expanded, and some pseudolobules were surrounded by fibrosis to form a fibrous septum in the EtOH group (Fig. 2D). In the anti-TLR4 and anti-MD-2 groups, collagen fiber deposition slightly decreased, the area of portal area had a slight reduction, and the fibrous septum was narrowed compared with that in the EtOH group (Fig. 2D). Next, the levels of proteins linked to liver fibrosis were detected, and it was found that TLR4 or MD-2 inhibition could also partially reverse the upregulation of collagen I, $\alpha$-SMA, and TIMP-1 induced by alcohol (Fig. 2E). ELISA results also indicated that the upregulation of hydroxyproline and ALT induced by alcohol was partially reduced by inhibiting TLR4 or MD-2 (Fig. 2F-G). The above results suggest that inhibition of TLR4 (53\%) and MD-2 (33\%) could partially alleviate alcohol-induced liver fibrosis in the model group of rats.

\section{Inhibition of TLR4/MD-2 could partially reduce the activation of $\mathrm{KCs}$ in liver fibrosis}

Next, using immunofluorescence, the levels of CD68, a biomarker of KCs in the rat liver, were determined. The staining results showed that after alcohol treatment, CD68 was highly expressed in the portal area. However, inhibition of TLR4 and MD-2 partially reduced the levels of CD68 (Fig. 3A). Western blotting analysis also revealed that alcohol-induced overexpression of CD68 and the inflammatory factors IL-1 $\beta$ and MIP-1 $\alpha$ was partially reversed upon treatment with antibodies against TLR4 and MD-2 (Fig. 3B). Furthermore, the results of the RT-qPCR test were also consistent with the Western blotting findings, suggesting regulation at the mRNA level (Fig. 3C). Overall, based on CD68 levels, the above results suggest that inhibition of TLR4 and MD2 could partially alleviate the activation of $\mathrm{KCs}$ in the liver of fibrotic rats.

\section{Knockdown of TLR4/MD-2 in KCs could partially reduce the activity of LPS-induced HSCs}

KCs were isolated and cultured as described in the Methods section. Next, RT-qPCR and Western blotting were used to estimate the levels of TLR4, MD-2, and TNF- $\alpha$. The results indicated that LPS 
upregulated the levels of TLR4, MD-2, and TNF- $\alpha$. However, the increase was partially reversed upon treatment with si-TLR4 and si-MD-2 (Fig. 4A-B). In addition, siRNA reduced the expression of TLR4 and MD-2 by 34\% and 37\%, respectively (Fig. 4B). When the levels of CD68 and pro-inflammatory factors IL-1 $\beta$ and MIP-1 $\alpha$ were estimated using RT-qPCR, it was found that LPS-induced increase in

CD68, IL-1 $\beta$, and MIP-1 $\alpha$ was also partially reduced by si-TLR4/si-MD-2 treatment (Fig. 4C). Similar results were obtained through Western blot analysis (Fig. 4D). HSCs are the key effector cells of liver fibrosis ${ }^{12}$. Therefore, we next studied the effect of TLR4 and MD-2 knockdown in KCs on the activity of HSCs. For this purpose, KCs and HSCs were co-cultured. The MTT assay revealed that LPS overactivated HSCs, whereas the inhibition of TLR4 and MD-2 partially restrained this overactivation (Fig. 4E). Next, we estimated the levels of $\alpha$-SMA and desmin, a biomarker of HSCs, through Western blotting. The results showed that LPS-induced increase in $\alpha$-SMA and desmin levels was partially inhibited by the knockdown of TLR4 and MD-2 (Fig. 4F). In brief, in vitro knockdown of TLR4 and MD-2 in KCs partially inhibited the activation of KCs and reduced the expression of pro-inflammatory factors, suggesting reduced activity of HSCs.

\section{Discussion}

This study established a rat model of hepatic fibrosis by treating rats with alcohol, which activated the TLR4/MD-2-TNF- $\alpha$ pathway. In a further study, it was found that inhibition of TLR4 and MD-2 partially decreased the activity of KCs and HSCs and partially relieved hepatic fibrosis in the model rats. The in vitro experiments indicated that LPS-induced activation of the TLR4/MD-TNF- $\alpha$ signaling pathway was partially inhibited by the knockdown of TLR4 and MD-2 in KCs. In addition, the release 
of pro-inflammatory factors and the activity of HSCs partially decreased. In other words, inhibition of TLR4 and MD-2 could partially alleviate alcohol-induced liver fibrosis in rats.

TLR4, a pattern recognition receptor, is mainly expressed in macrophages. It is linked to macrophage activation and the release of inflammatory factors ${ }^{35,36}$. MD-2 is a helper protein of TLR4, which assists TLR4 in recognizing LPS and interferes with LPS-induced inflammation ${ }^{37,38}$. A previous study in mice showed that monoclonal antibodies against TLR4/MD-2 could reduce LPS-induced acute hepatitis by inhibiting TNF- $\alpha^{39}$. Similarly, deficiency of TLR4 and MD-2 was reported to alleviate nonalcoholic liver fibrosis in mice ${ }^{40}$. Yin et al. reported that blocking the expression of TLR4 and MD-2 improved LPS-induced liver failure ${ }^{41}$. This evidence suggests that nonalcoholic liver disease is caused by LPS through the TLR4/MD-2-TNF- $\alpha$ signaling pathway. To explore whether alcoholic liver disease is also mediated by this pathway, a rat liver fibrosis model was established through the intragastric administration of alcohol, and in vitro studies in KCs were performed.

Earlier studies suggested that long-term drinking upregulates TLR4 in the liver and makes the organ more sensitive to LPS through the overexpression of TNF- $\alpha$ and IL- $6{ }^{42}$. Our study found that TLR4/MD-2 levels in the rat liver were increased after the intragastric administration of alcohol, along with the expression of TNF- $\alpha$. Notably, the inhibition of TLR4 reduced the secretion of TNF- $\alpha$ and IL-6, thus reducing alcohol-induced liver injury ${ }^{43}$. Our study also showed that upon TLR4/MD-2 inhibition, the degree of alcohol-induced liver injury was partially reduced, and the expression of proteins related to liver fibrosis was partially decreased. Akashi-Takamura et al. showed that mAb Sa15-21 protects rats from LPS/D-GalN-induced liver failure by activating NF- $\kappa$ B protective signaling through the TLR4/MD-2 pathway and influencing TNF- $\alpha$-induced hepatocyte apoptosis ${ }^{39}$. Our study showed that the inhibition of TLR4/MD-2 could inhibit the expression of TNF- $\alpha$ to reduce cell 
apoptosis, thus partially alleviating alcoholic liver injury in rats. Meanwhile, the mRNA levels of TLR4 and MD-2 were also partially reduced by the TLR4 and MD-2 antibodies. We speculate that this phenomenon may be related to a negative feedback regulation mechanism, that is, TLR4/MD-2 reduction inhibits the $\mathrm{NF}-\kappa \mathrm{B}$ signaling pathway and activates the $\beta$-catenin pathway, whereas the activation of the $\beta$-catenin pathway inhibits the TLR4/MD-2 pathway ${ }^{44,45}$. In the future, studies on the specific mechanisms may be needed. Besides, numerous evidences suggest that TLR4 induces activation of HSCs, which is an important transformation step for liver inflammation into liver fibrosis ${ }^{43}$. Alcohol-induced TLR4 expression activates HCSs via the TLR4/MD-2-TNF- $\alpha$ signaling pathway and promotes chemokine secretion. This increases the recruitment of KCs to the liver injury site, which releases pro-inflammatory factors that cause liver inflammation ${ }^{43}$. Our research indicates that KCs are activated by the alcohol-induced TLR4/MD-2-TNF- $\alpha$ signaling pathway, which promotes pro-inflammatory factors. Notably, this phenomenon was partially suppressed by inhibiting TLR4 and MD-2. Moreover, in vitro experiments showed that inhibition of TLR4 and MD-2 in KCs partially reduced the activation of KCs and HSCs and partially suppressed the LPS-induced release of pro-inflammatory factors. It has been found that ethanol can affect the integrity and permeability of the intestinal mucosa and destroy the barrier structure. Therefore, we infer that ethanol increases the possibility of LPS translocation from rat intestine, and LPS transported from the intestine of rats enters the systemic circulation through the gastrointestinal lymphatic vessels and portal vein and then participates in the production and development of liver inflammation. In addition, Akashi-Takamura et al. also proved that the monoclonal antibody sa15-12 of TLR4/MD-2 can alleviate the activation of KCs and inhibit hepatocyte apoptosis ${ }^{39}$. The antibodies used in our study have been shown to alleviate 
$\mathrm{KC}$ activation. However, whether these factors affect hepatocyte apoptosis needs to be confirmed in subsequent studies.

It is well known that reactive oxygen species (ROS) play an important role in ethanol metabolism in the liver ${ }^{46}$. The Nrf2/ARE signaling pathway is a hot topic in the field of liver fibrosis. Certain cell stimulations from ROS combine the nuclear transcription related factor-2 (Nrf2) with the antioxidant response element (ARE) promoter sequence and activates $\gamma$-glutamylcysteine ligase $(\gamma \text {-GCS })^{47}$. The synergistic effect of Nrf2 and $\gamma$-GCS is conducive to the body against free radicals, avoids hepatocyte damage, and then slows down the process of liver fibrosis ${ }^{48}$. Studies have shown that the Wnt/ $\beta$-catenin signaling pathway is involved in the formation of alcoholic liver fibrosis, which activates and proliferates HSCs, resulting in liver fibrosis ${ }^{49}$. It is possible that the activation of HSCs can be inhibited and the expression level of various liver fibrosis indices can be reduced by inhibiting the Wnt/ $\beta$-catenin signaling pathway to promote the recovery of liver fibrosis. A multipronged approach may completely alleviate liver injury caused by alcohol, which may be our future research direction.

In conclusion, alcohol activates KCs through the LPS-TLR4/MD-2-TNF- $\alpha$ signaling pathway, and KCs release inflammatory factors to activate HSCs, which led to liver fibrosis in model rats. However, inhibition of the LPS-TLR4/MD-2-TNF- $\alpha$ signaling pathway partially relieved liver fibrosis in model rats. Overall, this study provides a scientific basis for the prevention and treatment of alcoholic liver disease by suggesting new therapeutic targets.

\section{Acknowledgments}

None 


\section{Funding}

None

Disclosure of potential conflicts of interest

None 


\section{References}

1. Liu X, Wu Y, Yang Y, Li W, Huang C, Meng X, and Li J. Role of NLRC5 in progression and reversal of hepatic fibrosis. Toxicol Appl Pharmacol. 294: 43-53. 2016.

2. Zheng H, Wang X, Zhang Y, Chen L, Hua L, and Xu W. Pien-Tze-Huang ameliorates hepatic fibrosis via suppressing NF- $\mathrm{BB}$ pathway and promoting HSC apoptosis. J Ethnopharmacol. 244: 111856. 2019.

3. George J, Tsuchishima M, and Tsutsumi M. Molecular mechanisms in the pathogenesis of N-nitrosodimethylamine induced hepatic fibrosis. Cell Death Dis. 10: 18. 2019.

4. Shay JES, and Hamilton JP. Hepatic fibrosis: Avenues of investigation and clinical implications. Clin Liver Dis (Hoboken). 11: 111-114. 2018.

5. Zhou WC, Zhang QB, and Qiao L. Pathogenesis of liver cirrhosis. World J Gastroenterol. 20: 7312-7324. 2014.

6. George J, Tsuchishima M, and Tsutsumi M. Metabolism of N-nitrosodimethylamine, methylation of macromolecules, and development of hepatic fibrosis in rodent models. J Mol Med (Berl). 2020.

7. Shan L, Liu Z, Ci L, Shuai C, Lv X, and Li J. Research progress on the anti-hepatic fibrosis action and mechanism of natural products. Int Immunopharmacol. 75: 105765. 2019.

8. Wu H, Chen G, Wang J, Deng M, Yuan F, and Gong J. TIM-4 interference in Kupffer cells against CCL4-induced liver fibrosis by mediating Akt1/Mitophagy signalling pathway. Cell Prolif. 53: e12731. 2020.

9. Duffield JS, Forbes SJ, Constandinou CM, Clay S, Partolina M, Vuthoori S, Wu S, Lang R, and Iredale JP. Selective depletion of macrophages reveals distinct, opposing roles during liver 
injury and repair. J Clin Invest. 115: 56-65. 2005.

10. Lodder J, Denaës T, Chobert MN, Wan J, El-Benna J, Pawlotsky JM, Lotersztajn S, and Teixeira-Clerc F. Macrophage autophagy protects against liver fibrosis in mice. Autophagy. 11: 1280-1292. 2015.

11. Klingberg F, Hinz B, and White ES. The myofibroblast matrix: implications for tissue repair and fibrosis. J Pathol. 229: 298-309. 2013.

12. Qu C, Zheng D, Li S, Liu Y, Lidofsky A, Holmes JA, Chen J, He L, Wei L, Liao Y, Yuan H, Jin Q, Lin Z, Hu Q, Jiang Y, Tu M, Chen X, Li W, Lin W, Fuchs BC, Chung RT, and Hong J. Tyrosine kinase SYK is a potential therapeutic target for liver fibrosis. Hepatology. 68: 1125-1139. 2018.

13. Tsuchida T, and Friedman SL. Mechanisms of hepatic stellate cell activation. Nat Rev Gastroenterol Hepatol. 14: 397-411. 2017.

14. George J, Tsutsumi M, and Tsuchishima M. MMP-13 deletion decreases profibrogenic molecules and attenuates $\mathrm{N}$-nitrosodimethylamine-induced liver injury and fibrosis in mice. $\mathrm{J}$ Cell Mol Med. 21: 3821-3835. 2017.

15. Ying HZ, Chen Q, Zhang WY, Zhang HH, Ma Y, Zhang SZ, Fang J, and Yu CH. PDGF signaling pathway in hepatic fibrosis pathogenesis and therapeutics (Review). Mol Med Rep. 16: 7879-7889. 2017.

16. Huang Y, Deng X, and Liang J. Modulation of hepatic stellate cells and reversibility of hepatic fibrosis. Exp Cell Res. 352: 420-426. 2017.

17. Zhang CY, Yuan WG, He P, Lei JH, and Wang CX. Liver fibrosis and hepatic stellate cells: Etiology, pathological hallmarks and therapeutic targets. World J Gastroenterol. 22: 
10512-10522. 2016.

18. Tomita K, Tamiya G, Ando S, Ohsumi K, Chiyo T, Mizutani A, Kitamura N, Toda K, Kaneko T, Horie Y, Han JY, Kato S, Shimoda M, Oike Y, Tomizawa M, Makino S, Ohkura T, Saito H, Kumagai N, Nagata H, Ishii H, and Hibi T. Tumour necrosis factor alpha signalling through activation of Kupffer cells plays an essential role in liver fibrosis of non-alcoholic steatohepatitis in mice. Gut. 55: 415-424. 2006.

19. Osawa Y, Hoshi M, Yasuda I, Saibara T, Moriwaki H, and Kozawa O. Tumor necrosis factor- $\alpha$ promotes cholestasis-induced liver fibrosis in the mouse through tissue inhibitor of metalloproteinase-1 production in hepatic stellate cells. PLoS One. 8: e65251. 2013.

20. Yoshiji H, Kuriyama S, Miyamoto Y, Thorgeirsson UP, Gomez DE, Kawata M, Yoshii J, Ikenaka Y, Noguchi R, Tsujinoue H, Nakatani T, Thorgeirsson SS, and Fukui H. Tissue inhibitor of metalloproteinases-1 promotes liver fibrosis development in a transgenic mouse model. Hepatology. 32: 1248-1254. 2000.

21. Ma C, Liu A, Wang Y, Geng X, Hao L, Song Q, Sun B, Wang H, and Zhao G. The hepatocyte phase of Gd-EOB-DTPA-enhanced MRI in the evaluation of hepatic fibrosis and early liver cirrhosis in a rat model: an experimental study. Life Sci. 108: 104-108. 2014.

22. Shen X, Guo H, Xu J, and Wang J. Inhibition of lncRNA HULC improves hepatic fibrosis and hepatocyte apoptosis by inhibiting the MAPK signaling pathway in rats with nonalcoholic fatty liver disease. J Cell Physiol. 234: 18169-18179. 2019.

23. Iqbal U, Dennis BB, Li AA, Cholankeril G, Kim D, Khan MA, and Ahmed A. Use of anti-platelet agents in the prevention of hepatic fibrosis in patients at risk for chronic liver disease: a systematic review and meta-analysis. Hepatol Int. 13: 84-90. 2019. 
24. Tan Z, Liu Q, Jiang R, Lv L, Shoto SS, Maillet I, Quesniaux V, Tang J, Zhang W, Sun B, and Ryffel B. Interleukin-33 drives hepatic fibrosis through activation of hepatic stellate cells. Cell Mol Immunol. 15: 388-398. 2018.

25. Su GL. Lipopolysaccharides in liver injury: molecular mechanisms of Kupffer cell activation. Am J Physiol Gastrointest Liver Physiol. 283: G256-265. 2002.

26. Szabo G, and Bala S. Alcoholic liver disease and the gut-liver axis. World J Gastroenterol. 16: 1321-1329. 2010.

27. Mandrekar P, and Szabo G. Signalling pathways in alcohol-induced liver inflammation. J Hepatol. 50: 1258-1266. 2009.

28. Hu N, Wang C, Dai X, Zhou M, Gong L, Yu L, Peng C, and Li Y. Phillygenin inhibits LPS-induced activation and inflammation of LX2 cells by TLR4/MyD88/NF- $\mathrm{B}$ signaling pathway. J Ethnopharmacol. 248: 112361. 2020.

29. Miller AM, Horiguchi N, Jeong WI, Radaeva S, and Gao B. Molecular mechanisms of alcoholic liver disease: innate immunity and cytokines. Alcohol Clin Exp Res. 35: 787-793. 2011.

30. $\mathrm{X} \mathrm{Lu} \mathrm{1,} \mathrm{B} \mathrm{Wang,} \mathrm{Y} \mathrm{Xie,} \mathrm{C} \mathrm{Liu,} \mathrm{B} \mathrm{Fu.} \mathrm{[Dynamic} \mathrm{change} \mathrm{and} \mathrm{expression} \mathrm{of} \mathrm{matrix}$ metalloproteinase-2, -9 in alcoholic liver disease in rats.] Zhonghua Gan Zang Bing Za Zhi. 5:268-70. 2001.

31. Li PZ, Li JZ, Li M, Gong JP, and He K. An efficient method to isolate and culture mouse Kupffer cells. Immunol Lett. 158: 52-56. 2014.

32. Zhang Q, Qu Y, Li Z, et al. Isolation and Culture of Single Cell Types from Rat Liver [J]. Cells Tissues Organs, 2016, 201:253-267. 
33. Livak KJ, and Schmittgen TD. Analysis of relative gene expression data using real-time quantitative PCR and the 2(-Delta Delta C(T)) Method. Methods. 25: 402-408. 2001.

34. Hemmann S, Graf J, Roderfeld M, and Roeb E. Expression of MMPs and TIMPs in liver fibrosis - a systematic review with special emphasis on anti-fibrotic strategies. J Hepatol. 46: 955-975. 2007.

35. Yao L, Kan EM, Lu J, Hao A, Dheen ST, Kaur C, and Ling EA. Toll-like receptor 4 mediates microglial activation and production of inflammatory mediators in neonatal rat brain following hypoxia: role of TLR4 in hypoxic microglia. J Neuroinflammation. 10: 23. 2013.

36. Peng Y, Gong JP, Liu CA, Li XH, Gan L, and Li SB. Expression of toll-like receptor 4 and MD-2 gene and protein in Kupffer cells after ischemia-reperfusion in rat liver graft. World J Gastroenterol. 10: 2890-2893. 2004.

37. Miyake K. Endotoxin recognition molecules, Toll-like receptor 4-MD-2. Semin Immunol. 16: 11-16. 2004.

38. Re F, and Strominger JL. Separate functional domains of human MD-2 mediate Toll-like receptor 4-binding and lipopolysaccharide responsiveness. J Immunol. 171: 5272-5276. 2003.

39. Akashi-Takamura S, Furuta T, Takahashi K, Tanimura N, Kusumoto Y, Kobayashi T, Saitoh S, Adachi Y, Doi T, and Miyake K. Agonistic antibody to TLR4/MD-2 protects mice from acute lethal hepatitis induced by TNF-alpha. J Immunol. 176: 4244-4251. 2006.

40. Csak T, Velayudham A, Hritz I, Petrasek J, Levin I, Lippai D, Catalano D, Mandrekar P, Dolganiuc A, Kurt-Jones E, and Szabo G. Deficiency in myeloid differentiation factor-2 and toll-like receptor 4 expression attenuates nonalcoholic steatohepatitis and fibrosis in mice. Am J Physiol Gastrointest Liver Physiol. 300: G433-441. 2011. 
41. Yin X, Gong X, Jiang R, Kuang G, Wang B, Zhang L, Xu G, and Wan J. Emodin ameliorated lipopolysaccharide-induced fulminant hepatic failure by blockade of TLR4/MD2 complex expression in D-galactosamine-sensitized mice. Int Immunopharmacol. 23: 66-72. 2014.

42. Gustot T, Lemmers A, Moreno C, Nagy N, Quertinmont E, Nicaise C, Franchimont D, Louis H, Devière J, and Le Moine O. Differential liver sensitization to toll-like receptor pathways in mice with alcoholic fatty liver. Hepatology. 43: 989-1000. 2006.

43. Soares JB, Pimentel-Nunes P, Roncon-Albuquerque R, and Leite-Moreira A. The role of lipopolysaccharide/toll-like receptor 4 signaling in chronic liver diseases. Hepatol Int. 9: 659-672. 2010.

44. Ma B, Hottiger M O. Crosstalk between Wnt/ $\beta$-Catenin and NF- $\kappa B$ Signaling Pathway during Inflammation [J]. Frontiers in Immunology. 7:378-. 2016.

45. Bibo, Ke, Xiu-Da, et al. $\beta$-catenin regulates innate and adaptive immunity in mouse liver ischemia-reperfusion injury [J]. Hepatology. 57:1203-1214. 2013.

46. Singh S, Arcaroli J, Thompson D C, et al. Acetaldehyde and retinaldehyde metabolizing enzymes in colon and pancreatic cancers $[\mathrm{J}]$. Biological Basis of Alcohol Induced Cancer. 7: 281. 2017.

47. Tessoulin B, Descamps G, Moreau P, et al. PRIMA-1 met induces myeloma cell death independent of Nrf2 by impairing the GSH/ROS balance [J]. Blood. 124: 1626. 2016.

48. Lushehak V I. Free radicals, reactive oxygen species, oxidative stress and its classification [J].

Chemico Bio Int. 224: 16417. 2016.

49. Ling L, Nurcombe V, Cool S M. Wnt sigIlaling contmls the fate of mesenchymal stem cells [J].

433: 1-7. 2009. 


\section{Figure legends}

\section{Figure 1. Alcohol treatment induced liver fibrosis and activated the TLR4/MD-2-TNF- $\alpha$ pathway}

\section{in model rats}

In the alcohol-damaged liver of model rats, the molecules associated with liver fibrosis were upregulated, and the signaling pathway of liver fibrosis was activated. (A) Hematoxylin and eosin staining and (B) Masson staining were used to detect liver injury. The arrows indicate the portal area. Compared with that in the control group, the livers of rats in the $\mathrm{EtOH}$ group showed obvious pathological damage. (C) The levels of proteins related to liver fibrosis were detected by Western blotting, and data quantification was performed using ImageJ software; compared with that in the control group, the levels of proteins related to liver fibrosis in the EtOH group showed an obvious increase. (D-E) ELISA was used to determine the collagen-related markers (D) hydroxyproline and (E)

ALT. The results showed that hydroxyproline and ALT levels significantly increased in the EtOH group. (F-G) The levels of TLR4, MD-2, and TNF- $\alpha$ were detected by (F) Western blotting and (G) RT-qPCR, and quantitation was performed using ImageJ software. The expression levels of TLR4, MD-2, and TNF- $\alpha$ were significantly increased in the EtOH group. The scale bar is $20 \mu \mathrm{m}$ at high power and 80 $\mu \mathrm{m}$ at low power. $* * \mathrm{p}<0.01, * * * \mathrm{p}<0.001$, vs. the control group

\section{Figure 2. Inhibition of TLR4/MD-2 can partially alleviate alcohol-induced liver fibrosis}

Upon treatment with TLR4 and MD-2 antibodies, the expression of TLR4 and other molecules related to liver fibrosis was partially decreased, and the degree of injury was improved. (A-B) The levels of TLR4, MD-2, and TNF- $\alpha$ were detected by (A) RT-qPCR and (B) Western blot assays, which reveal that the antibodies of TLR4/MD-2 can partially inhibit the increase in TLR4, MD-2, and TNF- $\alpha$ 
induced by alcohol. (C) HE staining and (D) Masson staining were used to observe the degree of liver fibrosis in rats. The arrows indicate the portal area, and alcohol-induced liver fibrosis was partially relieved by inhibiting TLR4/MD-2. (E) Western blotting was used to determine the levels of proteins related to liver fibrosis, such as collagen I, $\alpha$-SMA, and TIMP-1, and data were quantified using ImageJ software. The increase in these proteins is partially relieved by antibodies of TLR4/MD-2. (FG) The expression of (F) hydroxyproline and (G) ALT is estimated by ELISA, and the increase in hydroxyproline and ALT induced by alcohol was partially relieved by antibodies of TLR4/MD-2. The scale bar is $20 \mu \mathrm{m}$ at high power and $80 \mu \mathrm{m}$ at low power. $* * * \mathrm{p}<0.001$ vs. the control group. ${ }^{\# \#} \mathrm{p}<$ $0.01,{ }^{\# \# \#} \mathrm{p}<0.001$, vs. the EtOH group

Figure 3. Inhibition of TLR4/MD-2 can partially reduce the activation of KCs

Upon treatment with TLR4 and MD-2 antibodies, the activity of KCs and the secretion of pro-inflammatory factors were partially inhibited in the liver. (A) Expression of the KC marker, CD68, was observed through immunofluorescence, revealing that the antibodies of TLR4/MD-2 can partially inhibit the expression level of CD68. (B) Western blotting and (C) RT-qPCR were used to estimate the levels of CD68 and pro-inflammatory factors TNF- $\alpha$, IL-1 $\beta$, and MIP- $1 \alpha$. The results showed that the inhibition of TLR4/MD-2 can partially inhibit the expression of these factors. The scale bar is $100 \mu \mathrm{m}$. $* * * \mathrm{p}<0.001$ vs. the control group. ${ }^{\#} \mathrm{p}<0.05,{ }^{\# \#} \mathrm{p}<0.001$, vs. the EtOH group

Figure 4. Knockdown of TLR4/MD-2 in liver KCs can partially reduce the LPS-induced activity of HSCs

KCs and HSCs were isolated and co-cultured. Inhibition of TLR4 and MD-2 in KC cells reduced the activity of HSCs. In addition, the secretion of pro-inflammatory factors was reduced. (A-B) The expression of TLR4, MD-2, and TNF- $\alpha$ was determined by (A) RT-qPCR and (B) Western blotting. 
The increase in TLR4, MD-2, and TNF- $\alpha$ induced by LPS can be partially inhibited by the siRNAs of

TLR4/MD-2. (C-D) The levels of CD68 and pro-inflammatory factors IL-1 $\beta$ and MIP-1 $\alpha$ were

detected by (C) RT-qPCR and (D) Western blotting, and data were quantified by Image J software. The expression levels of CD68, IL-1 $\beta$, and MIP-1 $\alpha$ were also partially inhibited by knocking down

TLR4/MD-2. (E) The viability of HSCs was estimated using the MTT assay. (F) Expression of $\alpha$-SMA and desmin, markers of HSCs, was estimated by Western blotting, and data were quantified using ImageJ software. The results indicated that the viability of HSCs was also partially inhibited by knocking down TLR4/MD-2. ${ }^{* * *}$ p $<0.001$ vs. the control group. ${ }^{\# \#}$ p $<0.01,{ }^{\# \#} \mathrm{p}<0.001$, vs. the LPS group. 
A

control

HE

(100x)

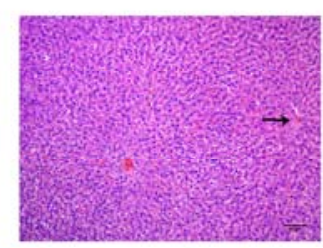

(400x)
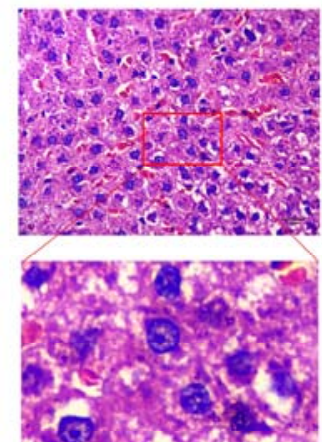

EtOH
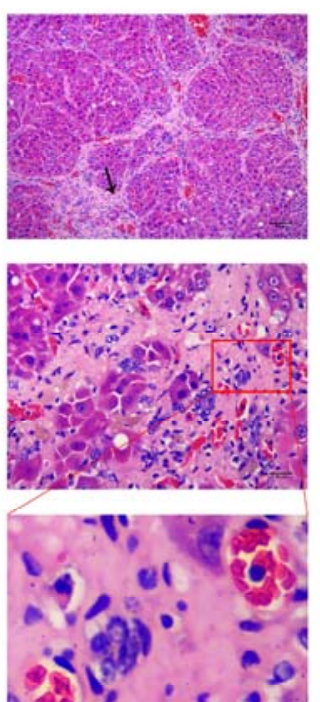

B

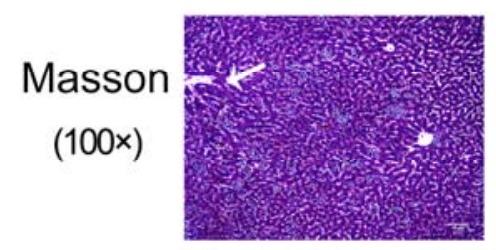

(400x)
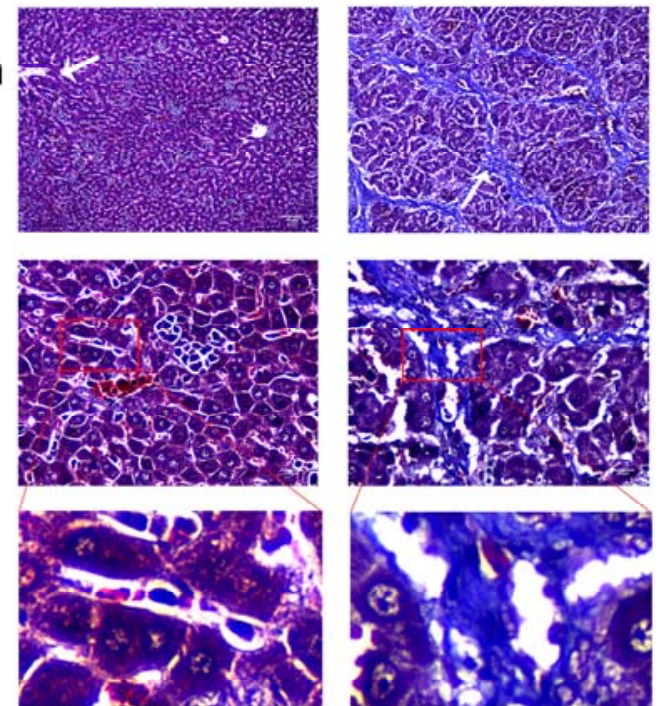

C

\section{control EtOH}

Collagen I

a-SMA

TIMP-1

$\beta$-actin
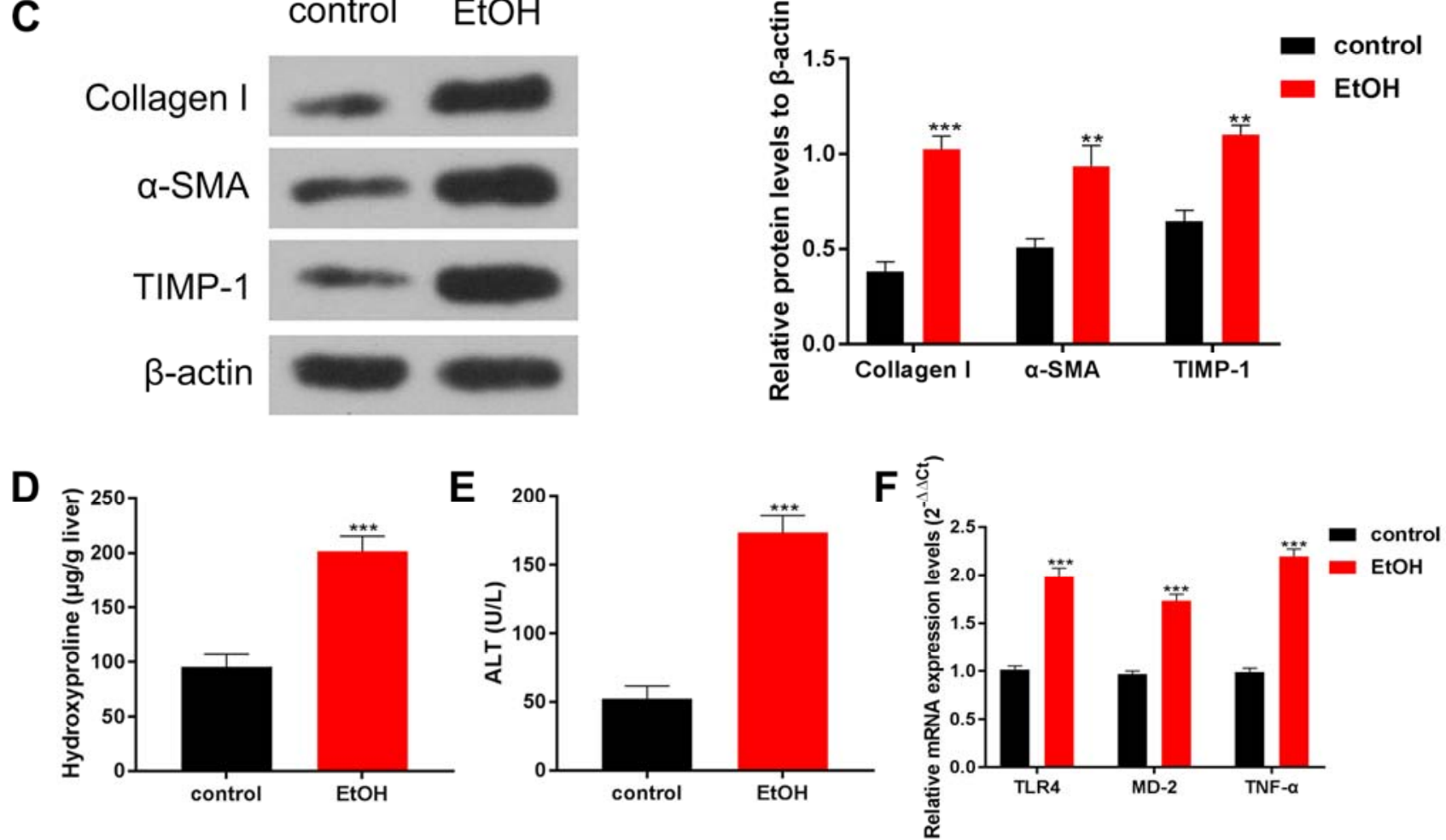

G
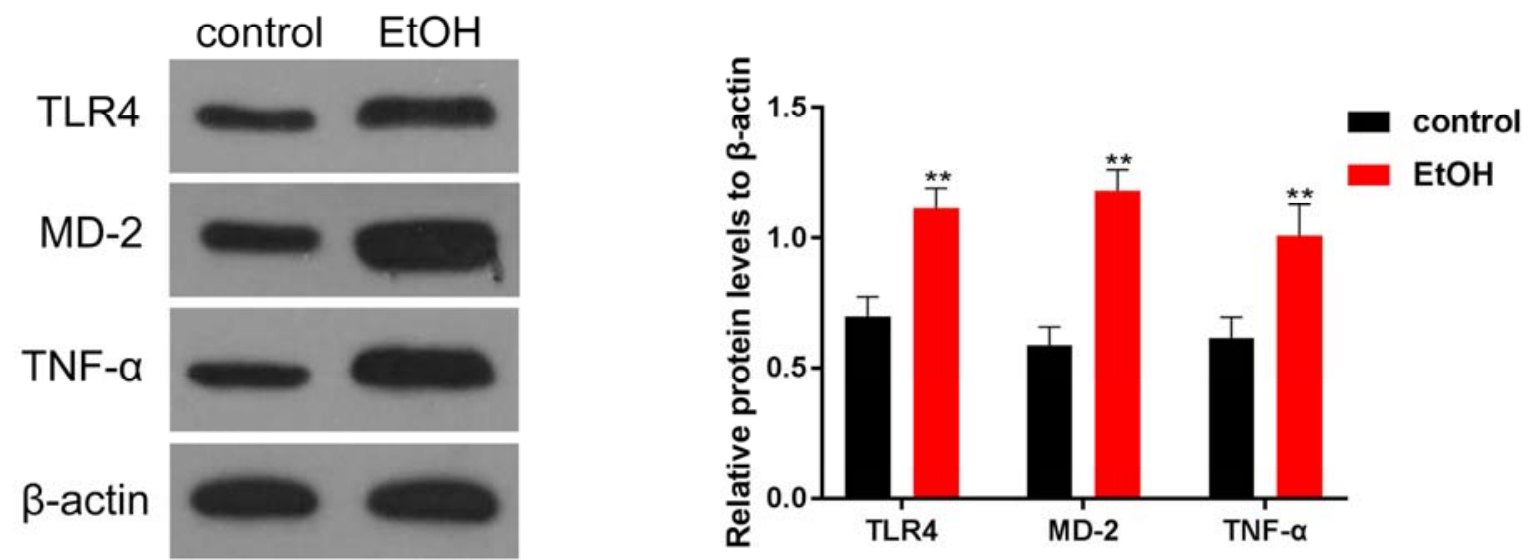


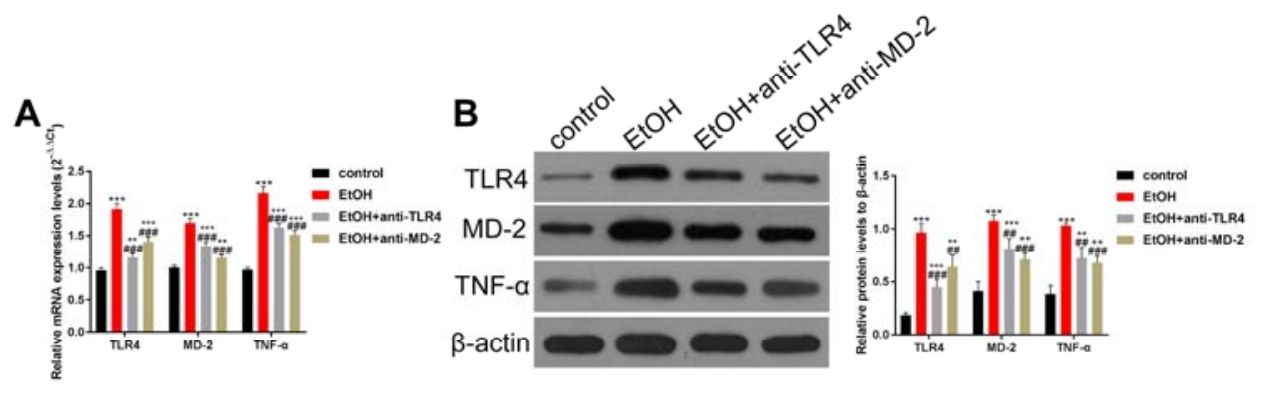

C
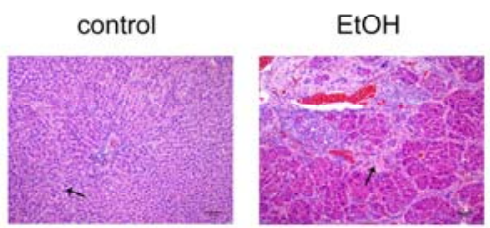

EtOH+anti-TLR4

EtOH+anti-MD-2

$(400 x)$
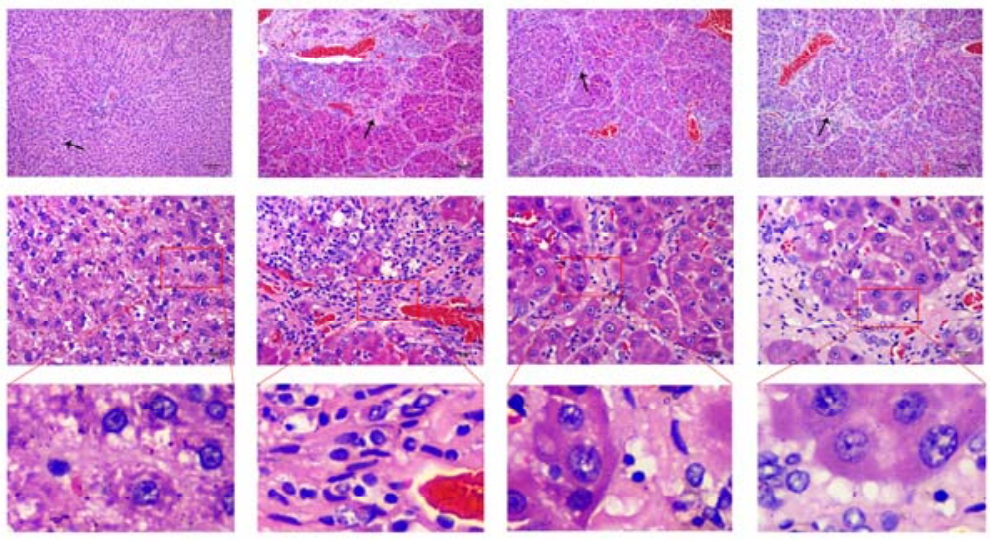

D

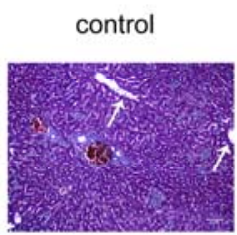

EtoH

EtOH+anti-MD-2

Masson

(100x)
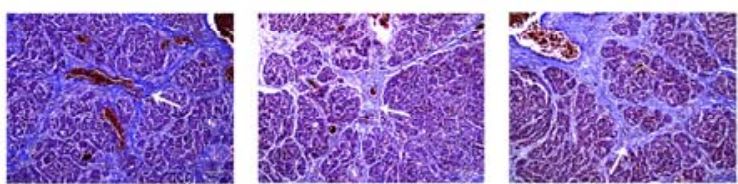

(400x)
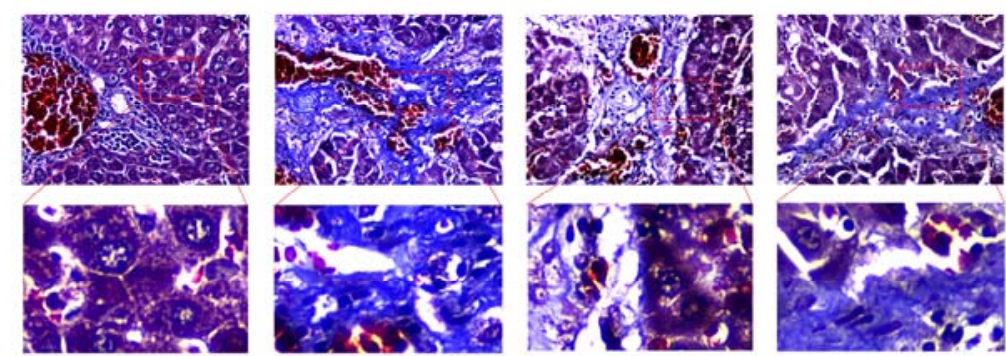

E
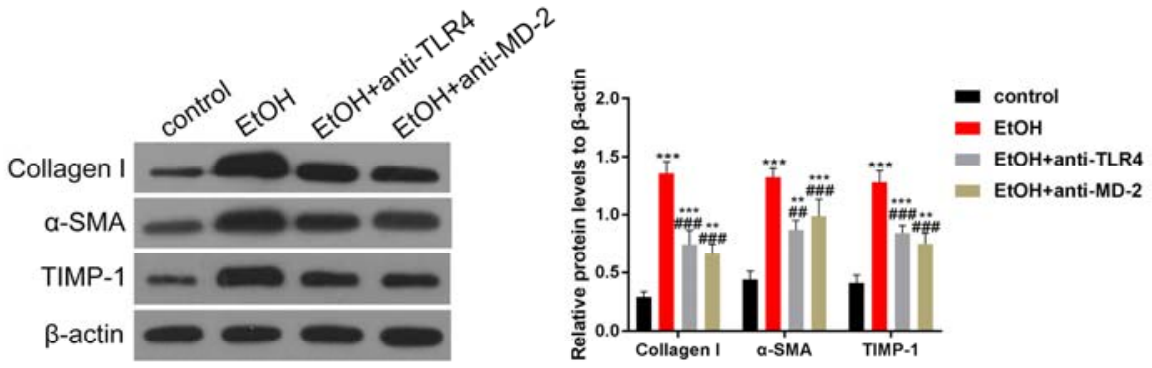

F

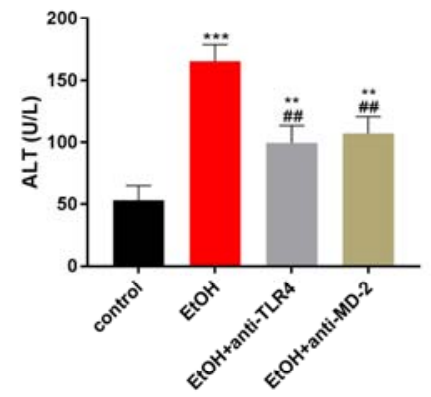

G

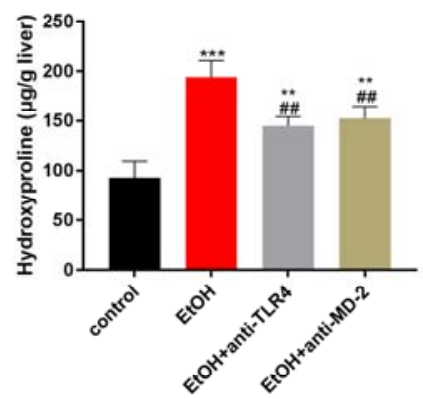


A

DAPI

CD68

Merge

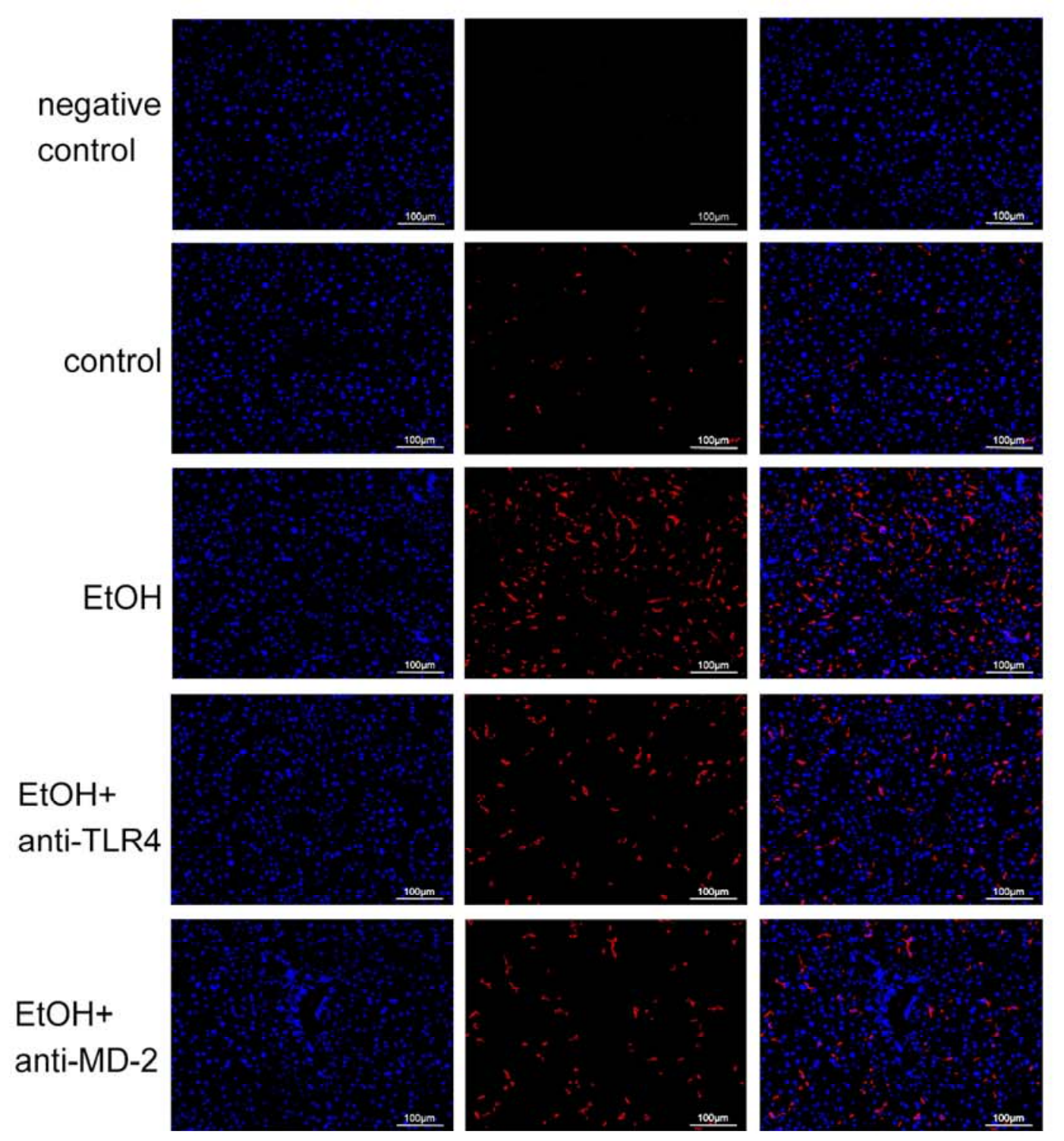

B

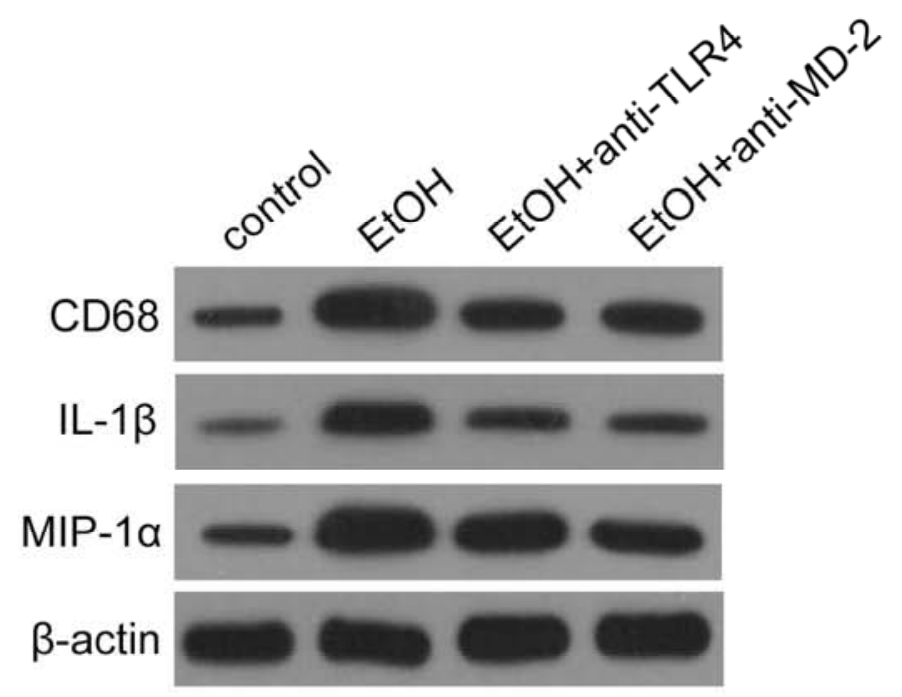

C
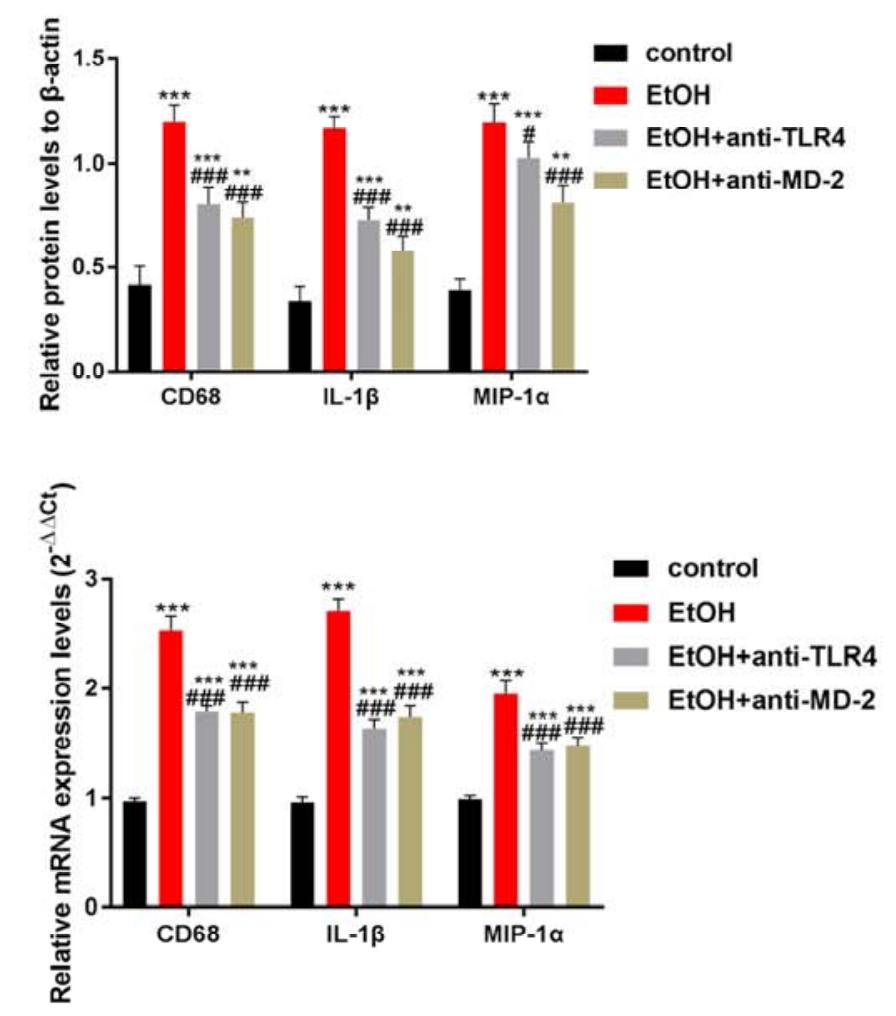
A

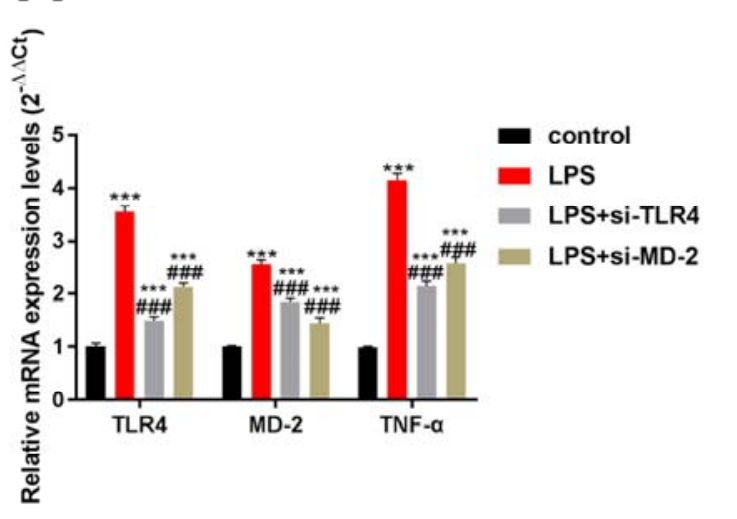

C

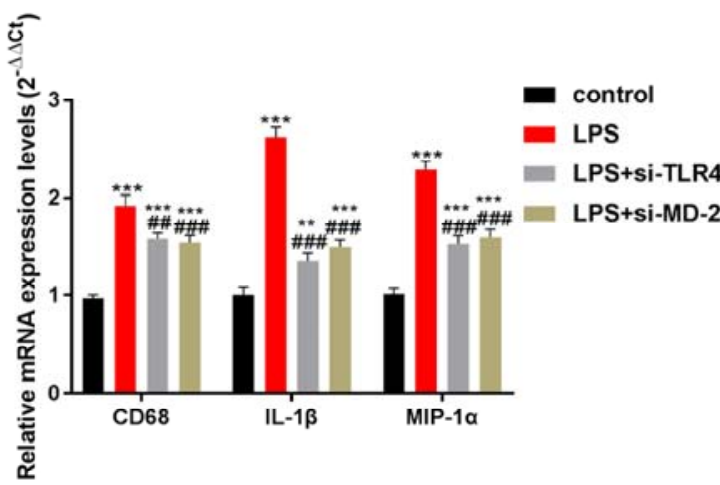

E

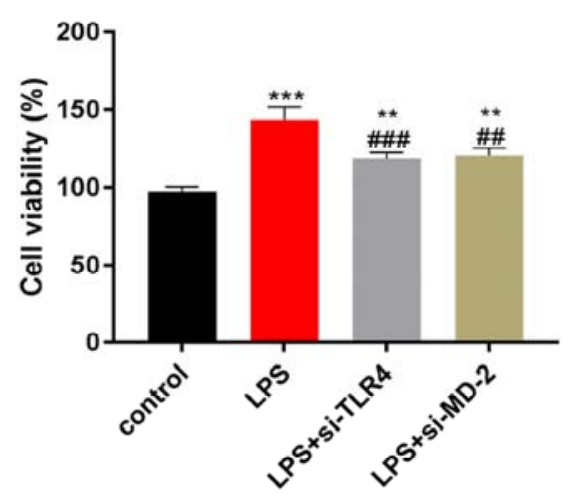

B
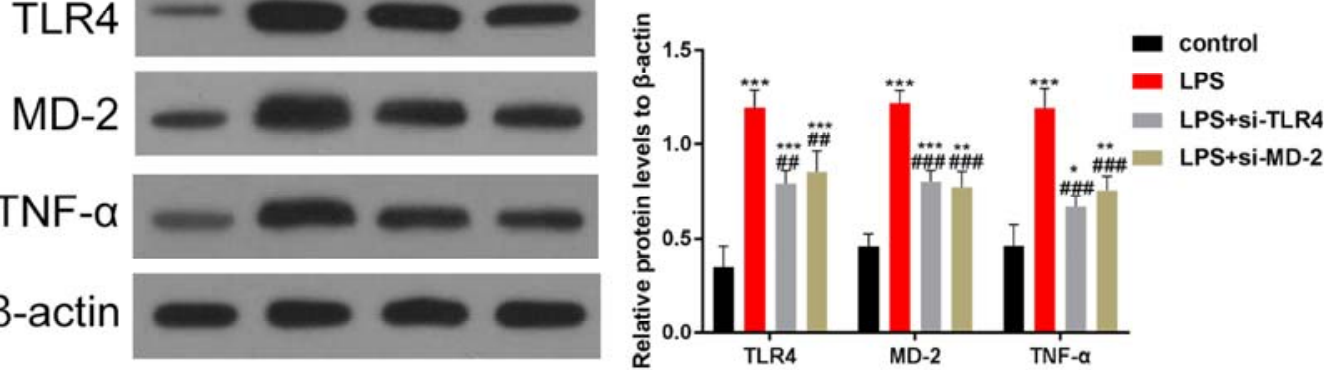

D
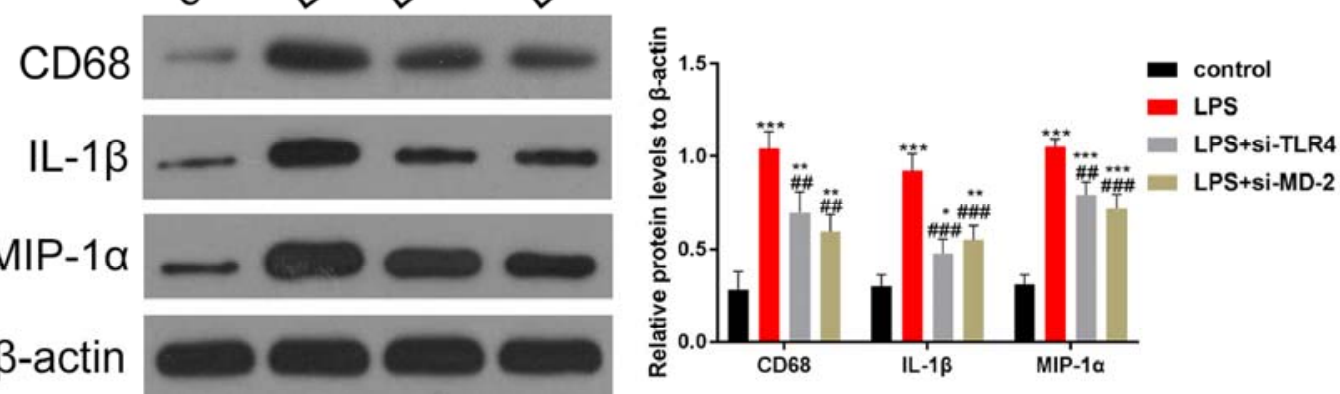

F

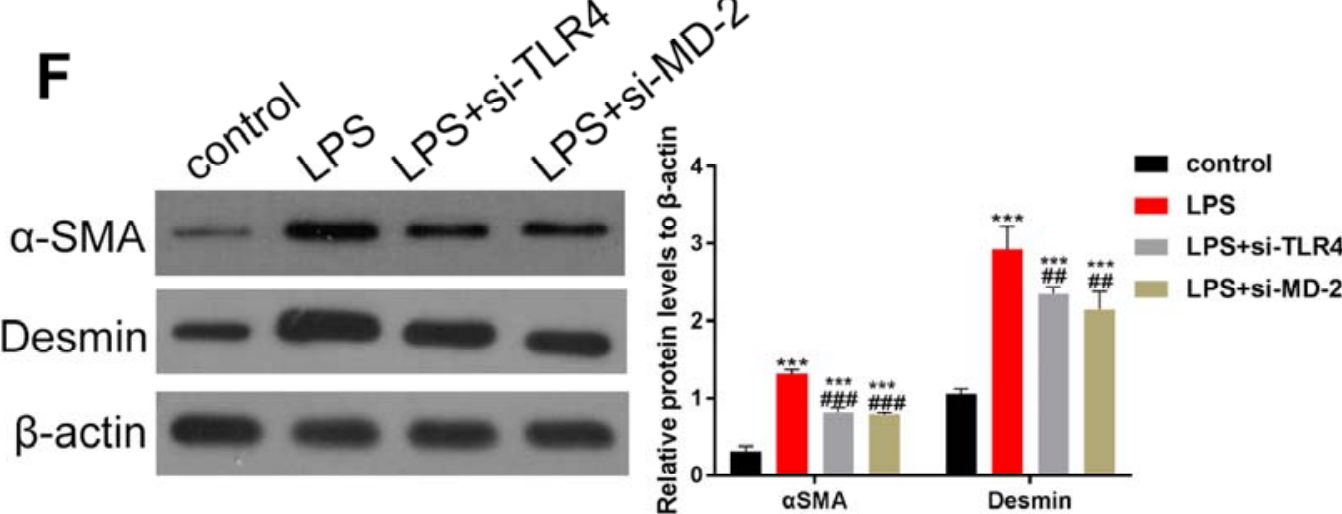


Table 1. The Primer Sequences of RT-qPCR

\begin{tabular}{|c|c|c|}
\hline Gene & Forward & Reverse \\
\hline TLR4 & $\begin{array}{l}\text { 5'-AGGATGAGGACTGGGTAAGG } \\
\text { A-3' }\end{array}$ & $\begin{array}{l}\text { 5'-CTGGA } \\
\text { TGAAGTGCTGGGACA-3' }\end{array}$ \\
\hline MD-2 & $\begin{array}{l}\text { 5'-GAAGCAGTATTGGGTCTGCA } \\
\text { A-3' }\end{array}$ & $\begin{array}{l}\text { 5'-TTGGAAGATTCATGGTGTTGAC } \\
\text { A-3' }\end{array}$ \\
\hline TNF- $\alpha$ & $\begin{array}{l}\text { 5'-CCAGAGGGAAGAGCAGTCC- } \\
\text { 3' }\end{array}$ & 5'-GGCTACAACGTGGGCTACC-3' \\
\hline CD68 & 5'-GCTTTGCAATCTCCCTGTTG-3 & 5'-TTGATCCGGGTTCTTACCTG-3' \\
\hline IL-1 $\beta$ & $\begin{array}{l}\text { 5'-TGCAGTTCACAGAGCAGACC } \\
-3 \text { ' }\end{array}$ & 5'-GACCGGAAACCTCATGGAG-3' \\
\hline MIP-1 $1 \alpha$ & $\begin{array}{l}\text { 5'-GCTGACCCCAAAGAGACCTG } \\
-3 \text { ' }\end{array}$ & 5'-CCCTGGATGTGGCTACTTGG-3' \\
\hline $\begin{array}{l}\text { GADP } \\
\mathrm{H}\end{array}$ & $\begin{array}{l}\text { 5'-GCACCGTCAAGGCTGAGAAC } \\
-3 \text { ' }\end{array}$ & 5'-ATGGTGGTGAAGACGCCAGT-3 \\
\hline
\end{tabular}

